\title{
La tensión interna al concepto de autonomía -autonomía, razones y republicanismo-
}

\author{
The internal tension to the concept of autonomy \\ -autonomy, reasons and republicanism-
}

Alessandro Caviglia Marconi ${ }^{1}$

\section{RESUMEN}

El presente trabajo busca aclarar algunos puntos centrales respecto de la tradición republicana, como el lugar que ocupa la justicia, el intercambio de razones y la autonomía en ella. Es por eso que comienza desarrollando una dilucidación de lo que se entiende por autonomía, del lugar que ocupa en la tradición moral de occidente, así como presentar la dialéctica interna al mismo concepto de autonomía, dialéctica nutrida por la exigencia de intercambio de razones. Una vez hecho eso, se presenta de qué manera el concepto de autonomía se inserta en la tradición republicana presentada por Philip Pettit, y de qué manera esta debe ser corregida tomando en cuenta la concepción de la justicia desarrollada por Rainer Forst.

\section{Palabras clave}

Autonomía, republicanismo, libertad, no dominación justicia, intercambio de razones

\section{ABSTRACT}

The present work search to clarify some central point with regard to the republican tradition such as the place that the justice occupies, the exchange of reasons and the autonomy in it. That is why starts developing a clarification of what is meant by autonomy, the place it occupies in the moral tradition of the West, as well as presenting the dialectic internal to the same concept of autonomy, dialectic nourished by the requirement of exchange of reasons. Once this is done, presents how the concept of autonomy is inserted in the republican tradition submitted by Philip Pettit, and how this should be corrected taking into account the conception of justice developed by Rainer Forst.

\section{Keywords}

Autonomy, republicanism, freedom, not domination justice, exchange of reasons

El término "autonomía", presente en la filosofía práctica que bebe de Kant, tiene varias aristas las cuales resultan por revelar una tensión interna. Esa vibrante tensión termina por desembocar en el intercambio recíproco de razones que es propio del proyecto normativo y político republicano. En un primer sentido, se entiende la autonomía como "autonomía de la Razón", es decir, la capacidad que tiene la Razón de autolegislarse independientemente de los imperativos de la naturaleza, o de las exigencias de la sociedad, o de las autoridades civiles, religiosas o militares. En un segundo sentido, la autonomía significa que las personas son capaces de determinar las leyes morales y jurídicas por sí mismas, gracias al ejercicio de sus poderes racionales. En un tercer sentido, la autonomía implica que las personas no pueden ser sometidas a dominación por parte de otras.

1 Magíster en Filosofía por la Pontificia Universidad Católica del Perú. Profesor del Departamento de Teología de la Pontificia Universidad Católica del Perú y de la Carrera Profesional de Filosofía de la Universidad Antonio Ruiz de Montoya. Ha publicado diversos artículos y ha presentado numerosas ponencias. 
De estas tres concepciones que se derivan de la idea kantiana de autonomía es posible derivar una relación dialéctica interna en el concepto mismo de autonomía (entre autonomía y heteronomía), que va de la razón autónoma a la relación con el otro (el momento heterónomo) para volver, finalmente, a una autonomía pasada por la intersubjetividad.

Es en este sentido que comenzaremos el presente trabajo, presentando los tres sentidos centrales del concepto de autonomía (1) para colocar sobre el tapete la cuestión de la tensión interna al mismo (2), y ver de qué manera la evolución del pensamiento moral occidental desde la revolución científica moderna cristaliza el concepto de autonomía (3). Una vez hecho eso, organizaremos la tensión inherente al concepto de autonomía en términos de una dialéctica interna al mismo (4). Finalmente, veremos de qué manera dicha dialéctica desemboca en la concepción relacional de lo normativo propio del republicanismo (5), pero como republicanismo se encuentra atrapado en una figura limitada de la justicia, pasaremos a una concepción del republicanismo que se conecta con una concepción adecuada de la justicia política, que coloca en su corazón el concepto de autonomía (6).

\section{1.- Los sentidos del concepto de autonomía}

El primer sentido de autonomía representa la posibilidad de la Razón para darse leyes a sí misma. El esfuerzo de la filosofía práctica consiste en que las exigencias morales sean racionales, en el sentido de que no dependan de fuente externa alguna, como los mandatos de alguna autoridad. De esta forma, "la autonomía de la Razón" expresa la "dignidad de la Razón”. La Razón declara como arbitraria toda exigencia que no provenga de sí misma, es decir, la declara como carente de racionalidad.

El segundo sentido de autonomía representa la posibilidad de que las personas puedan darse leyes gracias a que tienen la facultad de la razón. De esta manera, las personas se presentan como activas en vez de pasivas. Las personas son activas, en este sentido, ya que se representan a sí mismas como productoras de las normas, es decir, como sujetos morales; en cambio, las personas son representadas como pasivas cuando son vistas como objetos a los que se aplican las normas. De acuerdo con este segundo sentido del término "autonomía", un ser es pasivo ante las leyes cuando es considerado como un objeto. Aquí, las leyes son entendidas como elementos presentes en la naturaleza frente a la cual la cosa no tiene la posibilidad de ofrecer resistencia. Así, una piedra no opone resistencia a la ley de la gravedad y un cadáver no expresa su no consentimiento ante una voluntad externa. En cambio, la persona es entendida como sujeto de la ley, es decir, como activo, cuando es capaz de darse leyes a sí mismo y es capaz también de oponerse o cuestionar aquellas exigencias y leyes a las que no ha podido dar su propio consentimiento. De esta manera, la persona es entendida como sujeto porque es capaz de darse leyes a sí mismo y de expresar razones a favor o en contra de las exigencias que se le propone.

El tercer sentido de autonomía representa la posibilidad que tienen las personas de intercambiar entre sí razones en sentido normativo estándar (Scanlon, 2003:35-37). Aquí, la autonomía de las personas supone que ellas se encuentran en una relación en la que intercambian razones hasta que son capaces de llegar a las razones que pueden compartir. Aquí, las personas se encuentran en una relación de cooperación para arribar a las razones que pueden compartir. En este tercer sentido, la autonomía de las personas se quiebra cuando, en la relación interpersonal, una persona se ve forzada a aceptar una situación en la cual puede expresar sus razones en contra. Estas son las relaciones de víctima - victimario (Korsgaard, 1993:48-50). En este tipo de relaciones, el victimario no puede hacer oír sus razones respecto a que al mismo victimario no le agradarían (y, por lo tanto, tendría también él razones en contra) los tormentos que está obligado a padecer. En este tercer sentido, la autonomía forma su aspecto más relacional, $e$ incluye necesariamente una apelación a razones. Cuando la autonomía es vulnerada, decimos que la relación en la que las personas se encuentran es de dominación (Pettit, 1999:78-86). 


\section{2.- El problema del concepto de autonomía}

Los kantianos contemporáneos, como Thomas Scanlon, Christine Korsgaard, Jürgen Habermas y Rainer Forst, han cuestionado dos elementos centrales en el pensamiento de Kant, a saber, el apriorismo y el concepto de autonomía. Ciertamente, las críticas que los kantianos contemporáneos formulan contra Kant van más allá de estos dos cuestionamientos, pero podemos decir que estos son los cuestionamientos centrales.

A nosotros nos interesa la crítica al segundo concepto. Pero, es preciso señalar que la crítica a la autonomía va de la mano con la crítica al apriorismo. La idea de autonomía supone que la razón es la que produce las normas morales de modo completamente independiente de la experiencia y sin que medie la comunicación entre las personas. En un sentido fuerte, para Kant, cuando hablamos de autonomía nos referimos a la autonomía de la razón. Por este apartamiento de la razón autónoma respecto de la experiencia significa que esta produce de manera a priori las leyes morales. Es por eso que la ley moral es a priori, es decir, independiente de la experiencia, lo que significa que la ley moral (y la normatividad en general) no se extrae de la experiencia, sino que se impone a la experiencia bajo la forma de obligación.

Está claro que la crítica al concepto de autonomía se encuentra dirigida a la prima concepción de dicho término, que hemos anotado arriba. Y, esto se debe a que Kant le da un mayor peso a dicha interpretación de la autonomía frente a las otras dos, que han sido desarrolladas por los kantianos contemporáneos (Forst, 2014; Scanlon, 1996 y Korsgaard 2000). Ellos han hecho hincapié en los aspectos relacionales que se encuentran en el concepto de autonomía, con lo cual ha aparecido una tensión interna al mismo, tensión que vale la pena explorar para ver hacia dónde nos conduce. Esto resulta importante por el lugar que ha conseguido tener el concepto de autonomía tal como Kant lo ha presentado, en el desenvolvimiento de las ideas morales a partir de la revolución científica moderna. Es por esa razón que debemos entender qué sucedió con los conceptos morales una vez que se consolidó dicha revolución.

\section{3.- El lugar de la ética kantiana en el desarrollo del pensamiento moral en occidente}

En su libro Las fuentes de la normatividad, Christine Korsgaard nos permite entender por qué razones Kant plantea tanto la autonomía de la razón frente a la experiencia como el apriorismo de la ley moral. La explicación de la filósofa estadounidense tiene como centro lo que ella denomina la revolución moderna (Korsgaard, 2000:13-17). Dicha revolución consiste en una operación que permite colocar el mundo de cabeza. Antes de esta, en el mundo clásico, el valor era más real que el mundo de nuestras experiencias, a la vez que el valor mismo llamaba al mundo ( $y$ a los elementos que lo conforman) a acercarse a él. Es como si el valor le dijese al mundo y a sus elementos " $i V e n g a n$, sean como yo!". Pero el mundo incorporaba un elemento que le permitía responder a ese llamado que le hacía el valor, a saber, la excelencia. Es decir, los elementos del mundo encontraban su verdadera naturaleza en el conducirse hacia, y alcanzar, la excelencia. A través de esa naturaleza particular inherente al mundo, los elementos de este podían lograr su realización acercándose al valor. El ser humano, como un elemento más en el mundo, también respondía a ese llamado desarrollando un tipo de excelencia particular que denominamos virtud. Así como la excelencia es natural al mundo, la virtud es natural al ser humano. La virtud es como el lenguaje; se trata de una condición natural en el ser humano.

Según este modo de pensar compartido por Platón y Aristóteles, la realidad es el valor y el mundo adquiere su propia "realidad" conforme lo realice. Así, el despliegue de la verdadera naturaleza humana se da en la realización de las virtudes, que lo conduce a la eudaimonía. Con la modernidad, se concluye un proceso que ya estaba en ciernes en el mismo Platón y Aristóteles, pero que se encuadra mejor en el paso de la concepción teleológica y dinámica del mundo a la concepción matemática y mecánica del mismo, paso concluido con Galileo y 
Descartes². El cambio que esta revolución representa no significa que el valor pasa, de estar ubicado fuera del mundo, a estar ubicado dentro del mismo, sino que se trata de cambiar aquello que va a ser considerado la realidad. En el mundo clásico, la realidad era el valor, y el mundo era algo que despliega su realidad emulándolo. En cambio, tras la revolución moderna, el mundo es la realidad, una realidad dura, resistente, reluctante y mecánica. La realidad carece de fin y propósito específico. $\mathrm{El}$ valor no es inherente al mundo, tampoco se encuentra fuera del mundo llamándolo hacia sí. El valor ha perdido su realidad intrínseca para hacerse posible solo por medio del arte, es decir, como artificio humano.

El hecho de que el valor haya perdido su realidad intrínseca y se haya devenido un producto de arte tiene dos consecuencias. En primer lugar, no es que el arte no sea real, sino que ha perdido el lugar que tenía en el mundo clásico respecto del mundo. Afirmar que el valor, por ser producto de arte, ha perdido su realidad es como decir que este texto, por ser producto de arte carece de realidad. Como se puede advertir, dicho razonamiento es absurdo. En segundo lugar, una de las dimensiones del arte del que hablamos cuando señalamos que el valor es producto del arte es una idea que tiene dos dimensiones. La primera dimensión es que el contenido del valor no se encuentra ni en la naturaleza ni en el mundo metafísico, sino que es necesario que sea producido de alguna manera por la actividad artística del hombre. La segunda dimensión, que incorpora la idea de que el valor es producto del arte, consiste en introducirlo en la realidad (es decir, en ese mundo resistente y reluctante) en tanto producto del arte humano.

Dada la revolución moderna, el valor ha dejado de estar en el mundo como desarrollo de las virtudes a presentarse como obligación moral o ley moral. Tanto la determinación del contenido como la introducción en la realidad de la obligación moral se han convertido en un producto de arte. Pero para que dicha producción cuente como valor (tenga validez) necesitamos cerciorarnos que provenga de la fuente correcta. Es por eso que la investigación moral más importante desarrollada durante la modernidad es sobre la fuente de la normatividad. Entre los siglos XVI y XVIII, se desplegó esta revolución moderna, que incorporó un debate en torno a las fuentes de la normatividad.

Este debate pasó primero por las posiciones de Hobbes y Pufendorf, quienes asumieron el llamado voluntarismo, que consiste en asumir que la autoridad de las normas se encuentra en la voluntad de una autoridad. Pero, por los problemas que trajo esa posición, especialmente porque sus representantes no podían responder a la pregunta respecto de dónde proviene la autoridad misma de la autoridad que dicta la norma; por ese problema se abrió paso la posición llamada realista, que sostuvo que las normas morales tenían su valor solo por el hecho de que existen en el mundo. Así, realistas como Clarke y Price señalaron que el bien o el valor son entidades que se encuentran en la realidad y que uno podía conocerlas a través de una captación intelectual.

En el siglo XVII, quedó claro que la crítica de los realistas a los voluntaristas fue atinada y fulminante. Pero la respuesta de los realistas al problema de la fuente de la normatividad no resultó convincente. Tanto los voluntaristas como los realistas trataron de colocar la fuente de la normatividad fuera del ser humano, pero en vista de los fracasos de ambos, en el siglo XVIII se vio la necesidad de desplazar dicha fuente al interior del ser humano. El problema

2 Desde Platón se da cuenta de que en este mundo armónico el ser humano es lo que no va tan bien como los demás elementos. En el diálogo El Fedro Platón intenta explicar que esto se debe a la caída que sufre el ser humano al mundo sensible, pero la explicación queda sumergida en el misterio. Las razones porqué los seres humanos no funcionan tan bien como el resto de las cosas del mundo Platón las explica a través de un mito que se hunde en el misterio mismo. Aristóteles también da cuenta que hay seres humanos que por su naturaleza no pueden alcanzar la excelencia, a saber, los esclavos. Para ellos no corresponde otra cosa más que la ley. Por su parte, los herederos cristianos de Platón, especialmente San Agustín, asumieron el mito de la caída, pero para ellos siguió siendo un misterio. Por el hecho de la caída, el ser humano se encuentra sometido a la ley que tiene su origen en Dios debido a que éste no puede conseguir por sus propios medios la excelencia. De esta manera, en el mundo clásico y medieval ya encontramos razones para incorporar las exigencias morales en el planteamiento ético. Lo que no vamos a encontrar es la idea de un mundo mecánico, que es el elemento que va a expulsar la idea de excelencia. 
de los realistas consistía en que el intuicionismo del que echaron mano era difícil de sostener. La idea de que nuestra razón tenía la capacidad de captar realidades morales existentes en el mundo fue cuestionada duramente. Uno de los mayores críticos fue, sin duda, David Hume, quien desplazó la búsqueda de la fuente de la normatividad del exterior hacia el interior del ser humano. El filósofo escocés planteó la idea de que la fuente de la norma se encontraba en una reflexión en la que concurrían los sentimientos y la razón. Pero, el problema que siguió al planteamiento de Hume fue el que los sentimientos no contenían los elementos suficientes para asegurar la estabilidad al asentimiento reflexivo que se estaba buscando. Por ello, Kant fundará la fuente de la normatividad no en los sentimientos sino en la estructura reflexiva de la razón humana. Esto lo realizará Kant haciendo una apelación a la autonomía (Korsgaard, 2000:32-35).

La revolución que surge en la modernidad y el debate que ella supuso se completó en la apelación a la autonomía realizada por Kant. El filósofo alemán completó este proceso señalando que la fuente de la ley moral es la razón autónoma y a priori aquella facultad que produce de manera independiente la norma.

\section{4.- El problema del concepto kantiano de autonomía}

Kant estuvo en lo correcto en señalar que la obligación es producto del arte humano, y la razón, base adecuada para darle validez a dicho producto. Pero el problema de la respuesta de Kant en este punto es el aislamiento en el que la razón se sitúa para realizar ese trabajo. El problema se encuentra en la interpretación que el filósofo alemán le da a la autonomía, interpretación que incorpora la idea del apriorismo. Uno de los filósofos del siglo XVIII, que Kant admiraba sobremanera, se había percatado de que si las exigencias morales deberían ingresar en el mundo solo podrían hacerlo en las relaciones entre las personas. Rousseau se había percatado, efectivamente, que en las relaciones humanas donde las personas buscaban dejar atrás relaciones de dominación y convertirse en emancipadas unas ante otras, en dichas relaciones solo es posible que las exigencias morales pudiesen presentarse en el terreno de lo real. Lo que podemos mantener de Kant, después de retroceder a Rousseau, es la idea según la cual el valor no está en el mundo, sino que es fruto de arte y que este debe ingresar al mundo bajo la forma de obligación. Además, que la fuente del valor se encuentra en algo muy cercano a la razón, a saber, las razones. En las relaciones interpersonales, lo que nos exigimos son razones para poder aceptar las normas morales o de otra índole. Dichas razones deben ser suficientemente justificadas para que podamos aceptar las normas.

\section{1.- La dialéctica interna al concepto de autonomía}

Uno de los filósofos contemporáneos que ha volcado las ideas de Rousseau en una crítica contra Kant con mayor claridad es el norteamericano Thomas Scanlon. En su libro titulado Lo que nos debemos unos a otros señala lo siguiente:

Mientras que Kant trató de explicar la autoridad especial de las exigencias morales demostrando que se fundan en las condiciones de nuestra actuación racional, yo intento explicar la importancia y la autoridad distintivas de las exigencias de justificabilidad ante otros mostrando cómo otros aspectos de nuestras vidas y de las relaciones con otra gente implican esta idea. El resultado es una concepción de lo correcto y lo incorrecto que es, en términos de Kant, claramente heterónoma (Scanlon, 2003:20-21).

El concepto de autonomía incorpora una dialéctica interna. Se pasa de la autonomía a la heteronomía y se vuelve a una concepción depurada del concepto mismo de autonomía. Esta depuración se produce al introducir las relaciones interpersonales dentro del concepto de autonomía por medio de la exigencia de justificabilidad ante otros. De esta manera, Scanlon sigue a Rousseau para realizar esta depuración de la autonomía kantiana. 
Kant asentó el concepto de autonomía "en las condiciones de nuestra actuación racional". Es decir, se trata de la autonomía de la razón. De esta manera, la autonomía significa que la razón actúa independientemente, sin que el sujeto entre en relaciones con las otras personas. Es ella misma quien determina las exigencias morales sin que medie intersubjetividad alguna. Así, la manera en la que Kant plantea la autonomía no permite hacer justicia a la voz del otro, una vez que los poderes que Kant le atribuía a la razón se han visto cuestionados por la necesidad de introducir las relaciones entre las personas. Así, el gran cuestionamiento a la manera en la que Kant plantea el concepto de autonomía radica en que, como esta es la autonomía de la razón, no contempla la interacción entre las personas.

Es por ello que Scanlon presenta la necesidad de introducir la exigencia de la justificabilidad ante otros, en el proceso de elaboración de las exigencias morales. Scanlon identifica su proceder más con la perspectiva de Rousseau que con la de Kant, puesto que en el primero se presentan las exigencias como surgidas del intercambio relacional con los otros. Scanlon acusa su vertiente Rouseauniana cuando afirma con claridad que:

La idea de una disposición compartida a modificar nuestras demandas privadas con vistas a encontrar una base de justificación que otros también tengan razones para aceptar es un elemento central de la tradición del contrato social que se remonta a Rousseau (Scanlon, 2003:20).

De esta manera, Rousseau, a diferencia de Kant, dota de una estructura relacional a la elaboración de las exigencias morales. Por su naturaleza relacional es que Scanlon señala que la moral debe ser pensada como heterónoma. Pero la exigencia de justificabilidad introduce un elemento depurador, a saber, que en la relación las personas deben intercambiar razones que puedan entender como suficientes para el contexto específico en el que están insertos. Esta forma de heteronomía mediada por la justificabilidad conduce a una forma enriquecida de autonomía. Se trata del ejercicio de la autonomía en la misma relación entre las personas. Términos como no dominación o emancipación capturan la misma idea: que en la relación las personas se entiendan como emancipada, sin estar sometidas a dominación. En ese tipo de relaciones, se tiene el intercambio fluido de razones.

Resulta importante señalar que estas relaciones interpersonales se realizan en contextos concretos. De tal manera que las razones que se intercambian en la relación incorporan los elementos presentes en estos. Pero la contextualización de las relaciones interpersonales no debe entenderse como un giro hacia el relativismo. La idea central que defiende el relativismo no es que los debates se encuentren insertos con contextos concretos, sino que no es posible el debate, es decir, que no es posible el intercambio de razones.

\section{2.- Las razones}

El tercer sentido de autonomía, presentado al inicio de este trabajo, nos conduce directamente a la consideración respecto de las razones. Las razones brotan de la razón práctica y expresan consideraciones a favor de algo (Scanlon, 2003:34), consideraciones que hacen valer la autonomía de los sujetos en sus relaciones entre personas tanto en el ámbito político, social como al interior de una forma de vida. Lo que se exige es que el intercambio de razones sea fluido, es decir, recíproco (Alegría, 2017:311-315). El intercambio recíproco de razones permite que las personas establezcan relaciones de cooperación social para establecer términos de justicia social.

Ahora bien, para el intercambio recíproco, es decir, para entrar en relaciones de cooperación, no bastan conceptos y razones generales, sino que requerimos también razones personales o también denominadas razones de la parcialidad (Nagel, 1996:17-26). Tanto las razones generales como las razones personales, por separado, nos ofrecen una lectura moral del mundo coherente y abarcadora, pero que encaradas generan una antinomia. Como resultado de esta antinomia surge un principio de crítica y justificación, a saber, el principio de razón recíproca y mutua, de modo que la 
antinomia arroja como principio práctico la reciprocidad, que se encuentra a la base de las relaciones recíprocas.

Una buena justificación es, a la vez, general y recíproca (o mutua) (Forst, 2014:21-23). Las razones recíprocas surgen de relaciones interpersonales y son aquellas que no exigen ciertos privilegios sobre otros, o no proyectan sobre otros las propias necesidades e intereses, mientras que las razones generales no excluyen las objeciones de ningún afectado y se refieren a condiciones de la vida práctica que todos pueden admitir como necesarias. De esta manera, para realizar el examen de los principios morales o de justicia desde el punto de vista de su justificabilidad hemos de hacer caso a los individuos ante los principios se tienen que justificar. Hacer caso no es simplemente tomar en cuenta los intereses o captar las circunstancias objetivas; se trata, más bien, de prestar atención debida a las razones en contra de los principios propuestos.

\section{3.- Razones generales y razones personales}

El filósofo estadounidense Thomas Nagel desarrolla la diferencia entre valores relativos al agente y valores absolutos en Punto de vista desde ningún lugar. Por valores relativos al agente entiende aquellas metas y anhelos que las personas pueden tener, pero que carecen de fuerza normativa para otros. De esta manera, si alguien se propone escalar el Kilimanyaro no puede exigir moralmente a otras personas que se comprometan en ayudarlo a realizar aquella empresa. En cambio, los valores absolutos son aquellos que comprometen a todas las personas, independientemente de sus anhelos, intereses y metas particulares. Así, mientras que mi anhelo por escalar una montaña es un valor relativo al agente, la exigencia de ser veraces es un valor absoluto, puesto que, a diferencia del caso anterior, la exigencia que emana de él tiene fuerza normativa para todos.

Nagel señala en Igualdad y parcialidad que: "la ética y las bases éticas de la política tienen que entenderse brotando de la división que se da en cada individuo entre dos puntos de vista: el personal y el impersonal" (Nagel, 1996:11). El punto de vista personal se constituye por los deseos de los individuos, los intereses, los proyectos, los vínculos, las lealtades y los planes de vida que definen nuestros puntos de vista individuales. En cambio, el punto de vista impersonal representa las exigencias de la colectividad, plantea sus demandas a cada individuo $y$ produce en cada uno de nosotros una potente exigencia de imparcialidad e igualdad universal. La posibilidad del punto de vista impersonal se basa en un proceso que, si bien toma en cuenta que la mayor parte de nuestra experiencia del mundo y de nuestros deseos pertenece a nuestro punto de vista individual, también somos capaces de pensar sobre el mundo haciendo abstracción de nuestra posición particular en él -haciendo abstracción de quiénes somos-. En la teoría ética, lo único que cuenta es hacer abstracción de nuestra identidad (esto es, quiénes somos).

Esta distinción de Nagel entre el punto de vista personal y el punto de vista impersonal arroja como resultado la distinción entre valores personales y valores impersonales. Puesto que los valores se encuentran vinculados estrechamente a las razones que los sustentan, la distinción entre valores impersonales $y$ personales puede traducirse, sin dificultad, en razones impersonales (o generales) y razones de la parcialidad (o razones personales). Así, si bien todos tenemos un aspecto de nuestra identidad humana en la que tienen preponderancia nuestros anhelos, metas $y$ valores personales, por otra parte, tenemos otro aspecto que nos descentra y que nos permite conectarnos con razones impersonales y generales. Entonces, el problema de la ética consiste, principalmente, en conjugar ambos lados de la identidad moral de las personas. Los intentos en ética y política de tomar solo uno de los lados, se han mostrado como fallidos. Por ejemplo, Hobbes asumió solamente el lado de las razones personales para fundar su teoría política, mientras que Bentham asumió solo el de las razones generales para su teoría moral y política, al igual que los regímenes comunistas.

Lo que queda claro del estudio de las obras de Nagel es que asumir solo uno de los aspectos conduce al fracaso en la teoría ética y política. 
Para poder llegar a buen puerto, es necesario buscar formas de articulación, o al menos de acomodo. Lo que sí es necesario tener presente es que desde cada lado es posible tener una concepción coherente, pero parcial, de la ética y la política. De hecho, la teoría de Hobbes como la de Bentham son coherentes, pero también parciales. Esto hace que entre las razones generales y las razones personales se forme una antinomia. Christine Korsgaard dará respuesta a dicha antinomia dándole un giro práctico a los términos. En cambio, de mantenerse en el esquema de la ética y de la política que se articula en torno a la pregunta "¿quién da qué a quién?", asume la perspectiva rawlsiana de la cooperación social e interpersonal basada en la pregunta "¿qué razones podemos compartir?". La respuesta a esa pregunta es que las razones que podemos compartir son aquellas que son generales a la vez que recíprocas (Korsgaard, 1993:24).

Este giro arroja un principio práctico que es el de la no instrumentalización de las personas, pues en este giro se exige considerar a la persona como centro de razones. En términos políticos, este giro nos conduce a considerar seriamente las ideas del republicanismo, pues este enarbola la bandera de la libertad como no dominación.

\section{5.- El Republicanismo}

Uno de los filósofos que ha esclarecido de mejor manera lo que significa el republicanismo es, sin duda, Philip Pettit. En su libro Republicanismo, ha señalado que dicho proyecto político hunde sus raíces en los ideales de la república romana con Cicerón y que va a ser retomado por los representantes de las repúblicas italianas del renacimiento, especialmente por Maquiavelo; en el siglo XVII, con Harrington, y en el siglo XVIII, con Thomas Paine y los precursores de la independencia norteamericana. Durante el siglo $\mathrm{XX}$, las ideas republicanas fueron retomadas de manera significativa por muchos intelectuales, entre los que destaca Quentin Skinner.

De acuerdo con Pettit, el republicanismo se encuentra comprometido con la idea de la libertad como no dominación (Pettit, 1999:21). Isaiah Berlin había popularizado la distinción entre libertad negativa y libertad positiva. En su célebre trabajo titulado Dos conceptos de libertad señala que la libertad negativa consiste en la libertad de no interferencia. De esta manera afirma que:

Normalmente se dice que soy libre en la medida en que ningún hombre ni grupo de hombres interfiere en mi actividad. En este aspecto, la libertad política es, simplemente, el espacio en el que un hombre puede actuar sin ser obstaculizado por otros. Si otros me impiden hacer algo que antes podía hacer, entonces soy en esa medida menos libre; pero si ese espacio es recortado por otros hombres más allá de lo admisible, entonces puede decirse que estoy siendo coaccionado o hasta esclavizado (Berlin, 2012:208).

En este sentido, la libertad negativa demarca un campo de acción de las personas. Campo que no debe ser vulnerado por ningún otro agente. Esta libertad se llama "negativa" porque exige la no intervención de otros en mi campo de acción. En cambio, la libertad positiva es definida por el pensador formado en la escuela anglosajona como la capacidad de autodeterminación. En este sentido, señala que:

El sentido "positivo" de la palabra "libertad" se deriva del deseo por parte del individuo de ser su propio amo. Quiero que mi vida y mis decisiones dependan de mí mismo, $y$ no de fuerzas exteriores, sean éstas del tipo que sean. Quiero ser el instrumento de mis propios actos voluntarios y no de otros hombres. Quiero ser un sujeto y no un objeto; quiero persuadirme por razones, por propósitos conscientes míos y no por causas que me afecten, por así decirlo, desde fuera. Quiero ser alguien, no nadie; quiero actuar, decidir, que no decidan por mí; dirigirme a mí mismo y no ser accionado por una naturaleza externa o por otros hombres como 
si fuera una cosa, un animal o un esclavo incapaz de jugar mi papel como humano, esto es, concebir y realizar fines y conductas propias (Berlin, 2012:217).

Siguiendo las ideas de Benjamin Constant, Berlin va a asociar la libertad positiva con la libertad de los antiguos, y la negativa con la libertad de los modernos. Así, el paradigma de la libertad positiva será Aristóteles, y el de la libertad de los modernos será Thomas Hobbes. Además, Berlin asocia a Rousseau, a Kant y a Hannah Arendt con la libertad de los antiguos, en cambio, a Locke y a John Stuart Mill con la libertad de los modernos. Pero hay más. Según Berlin, la libertad negativa es el tipo de libertad que debemos elegir, porque la libertad positiva esconde la amenaza de que la Razón o alguna persona que hable a nombre de ella pretenda restringir la libertad de los demás en nombre de la "verdadera" realización, o libertad o de cualquier otro fin. Es por eso que Berlin puede ver en Rousseau o en Kant enemigos encubiertos de la libertad (Berlin, 2012:229). Por esas razones su defensa de la libertad negativa lo convierte en un pensador liberal.

Pettit sostiene que existe una tercera concepción de la libertad que Berlin no tomó en cuenta. Se trata de la concepción que ha estado enarbolando la larga tradición republicana, a saber, la de libertad como no dominación. Esta concepción articula aspectos de la libertad negativa y de la libertad positiva. De la libertad negativa toma la idea de la ausencia; pero no se trata de ausencia de interferencia, sino ausencia de estar sometido al poder y al capricho de otro u otros. En cambio, de la concepción positiva de libertad asume la idea de dominación o dominio. Pero no se trata de tener el dominio sobre uno mismo, sino en el sentido de no encontrarse bajo el dominio de otro $u$ otros.

El tipo de relación que Pettit utiliza para esclarecer la idea de libertad como no dominación es la relación entre el amo y el esclavo. Esta relación ha sido importante para la tradición republicana desde la Roma republicana. La relación amo - esclavo representa el paradigma de la ausencia de libertad, puesto que el esclavo se encuentra bajo el poder arbitrario del amo. El amo puede someter a cualquier tipo de trato a su esclavo en cualquier momento o en cualquier lugar. El esclavo se encuentra profundamente dominado por el amo. Incluso si se trata de un amo bondadoso o beneficiente que decide dejar que su esclavo actúe conforme a su parecer, la relación de poder que ejerce sobre él no desaparece, porque la posibilidad real de que el amo bondadoso decida intervenir en la vida del esclavo se encuentra presente.

Ahora bien, la concepción de libertad como no dominación que proviene del republicanismo difiere de la concepción liberal de libertad como no interferencia. Es importante distinguir la dominación de la interferencia. La dominación es siempre interpersonal, es decir es ejercida por una persona (o un grupo) sobre otra persona (o grupo). En cambio, la interferencia puede ser personal, pero también puede ser impersonal. El caso del derecho es el de un sistema impersonal de interferencia, y si ese sistema jurídico no está a merced del interés de una persona o un grupo, estamos ante el caso de un sistema de interferencia, pero sin dominación. También puede haber interferencia personal sin dominación. Por ejemplo, el caso de una persona que le encarga a otra que se haga cargo de su dieta y de su régimen de ejercicios le está pidiendo a esta que interfiera en su vida. Pero esta forma de interferencia no implica dominación, porque la persona interferida cuenta con el poder de terminar con la relación de interferencia cuando lo considere conveniente.

De esta manera, puede haber no dominación con interferencia o no interferencia con dominación. Del mismo modo, puede haber interferencia con dominación y no interferencia con no dominación. Al mismo tiempo, la interferencia puede ser personal o impersonal, en cambio la dominación es siempre personal. El derecho justo es un ejemplo de interferencia impersonal sin dominación; en cambio, el caso del controlador de la dieta es uno de interferencia personal sin interferencia. Por otro lado, el caso del amo benevolente es uno de dominación sin interferencia y el caso del marido que somete a la mujer es un caso de dominación acompañado de interferencia. 
Así, el liberalismo interpreta la libertad como no interferencia y considera que la actividad política debe buscar terminar con la interferencia. En este punto se encuentran posiciones como la de Hobbes, Bentham, Stuart Mill, Berlin, Rawls o Nozick. En cambio, el republicanismo interpreta la libertad como no dominación y se plantea el objetivo político de terminar con la dominación. Ejemplos de republicanos son Cicerón, Maquiavelo, Locke, Harrington, Paine, Rousseau, Kant o Skinner. ¿Por qué la posición republicana es superior a la liberal?, porque puede existir dominación sin interferencia, y eso no significa que las personas sean libres (como en el caso del amo bondadoso), así como puede haber interferencia sin dominación (como en el caso del derecho justo) y ello no implica pérdida de libertad. De hecho, el derecho justo es un vehículo para la libertad y no un impedimento. Pettit señala que:

La condición de libertad se ilustra con el estatus de alguien que, a diferencia del esclavo, no está sujeto al poder arbitrario de otro, esto es, de alguien que no está dominado por el poder arbitrario de ningún otro. Así, la condición de libertad queda ilustrada de modo tal, que puede haber pérdida de libertad sin que se dé interferencia real de tipo alguno: puede haber esclavización y dominación sin interferencia, como en el ejemplo del amo que no interfiere (Pettit, 1999:51-52).

Entonces, el objetivo político debe ser el combate de la dominación. Pettit define la dominación en los siguientes términos:

Un agente domina a otro, si y solo si tiene cierto poder sobre ese otro, $y$ en particular, un poder de interferencia arbitrariamente fundado...Tiene potestad sobre otro... y esa potestad es arbitraria (Pettit, 1999:78).

Y, más abajo continúa señalando que:

Hay tres aspectos a considerar en una relación de dominación.
Prescindiendo de matices en la formulación de esos aspectos, diremos que alguien tiene poder de dominación sobre otro, en la medida en que:

1. Tiene capacidad para interferir

2. De un modo arbitrario

3. En determinadas elecciones que el otro pueda realizar (Pettit, 1999:78).

La dominación es un poder que una persona tiene sobre otra que le permite a la primera interferir de manera arbitraria en las elecciones de la segunda. El objetivo político del republicanismo consiste, pues, en combatir dicho poder para conseguir la emancipación de la persona (o el grupo) subyugada. Lograr vencer dicho poder sería restituir la autonomía de la persona en cuestión, entendiendo el término autonomía de la manera en la que la hemos comprendido. Se trata de una autonomía inserta en relaciones interpersonales y que se encuentra basada en el intercambio fluido de razones.

\section{6.- Republicanismo y autonomía}

El republicanismo presentado por Pettit es entendido como "negativo", en el sentido que basa en la idea de la libertad como no dominación. El filósofo irlandés señala que una de las diferencias sustantivas entre el liberalismo y el republicanismo es que mientras el primero puede realizarse en una situación asocial, el segundo requiere siempre de insertarse en un contexto social. Pettit señala:

La diferencia esencial entre la noción liberal y republicana de libertad solo se vuelve evidente cuando observamos una última distinción entre los valores políticos. Se trata de la distinción asocial-social: la distinción entre los valores de los que puede gozar una persona, en principio, fuera del contexto social y los valores para los que esa posibilidad no es válida...en este sentido, es un valor asocial, mientras que la igualdad con los demás -al menos 
en su interpretación natural- no lo es. Resulta que la libertad negativa, libertad en el sentido en el que por definición no requiere ninguno de los factores adicionales mencionados, puede interpretarse de ambos modos, como social o como asocial. La interpretación asocial es la liberal; la social es la republicana (Braithwaite y Pettit, 2015:75).

En este sentido, Pettit interpreta que la diferencia entre el liberalismo y el republicanismo consiste en la relación sociedad - libertad ley. Para el liberalismo, es posible tener libertad fuera de la sociedad (como en el caso de Hobbes) o tenerla dentro de la sociedad. Pero en el segundo caso, la ley es un instrumento para conseguir la libertad, mas no un elemento intrínseco de la libertad misma. En cambio, el republicanismo considera que la ley es un elemento intrínseco a la libertad. Para Pettit el republicanismo, comparte con el liberalismo la búsqueda de la libertad de no estar interferido. La ley haría que la interferencia no sea arbitraria, por eso se trata de un elemento esencial. En cambio, el liberalismo apuntaría a la no interferencia sin tener en cuenta el vínculo interno con la ley. En este sentido, Pettit señala que:

En esencia, esta visión se reduce a que la convención social y la ley no constituyen más que un medio para alcanzar la felicidad, y la índole del medio no importa mientras las personas dispongan del margen de elección que requiere la libertad (Braithwaite y Pettit, 2015:76).

El filósofo alemán Rainer Forst ha argumentado a favor una versión positiva del republicanismo, a diferencia de la concepción negativa del republicanismo presentado por Pettit. La posición de Forst incorpora dos elementos a la concepción republicana. Pero dicha incorporación termina por modificar sustantivamente las mismas ideas republicanas. Esto lo hace el filósofo de la Escuela de Frankfurt en dos pasos. El primero consiste en redefinir la concepción republicana, pasando de la concepción de la "libertad" como no dominación a la "justicia" como no dominación. El segundo paso consiste en introducir el concepto de autonomía de manera sustantiva en la concepción republicana. A través de estos dos pasos, lo que Forst consigue es articular de mejor manera una concepción kantiana del republicanismo.

\section{1.- De la concepción republicana de "libertad" como no dominación a la concepción de "justicia" como no dominación}

Forst señala que la concepción republicana de Pettit adolece de un problema central, a saber, se encuentra atrapada en una concepción de la justicia que no permite establecer el vínculo entre justicia, autonomía y libertad de manera adecuada. Es en ese sentido que Pettit señala que existen dos figuras de la justicia: La primera figura de la justicia se centra en la pregunta ćquién debe qué a quién? De acuerdo con esta pregunta, la justicia consistiría en seguir las pautas de un sistema previamente establecido que indica quién merece qué cosa. Esta forma de pensar la justicia fue formulada por Platón en $L a$ República y la define como dar a cada cual lo suyo, es decir, lo que merece por justicia. Claro está que la forma de definir quién merece qué cosa no es a través de algún debate basado en razones, sino en la posición del filósofo.

Esta primera figura de la justicia coloca a las personas en posición de pasivos y se centra en los objetos que se distribuyen. Con esto, lo que hace esta figura es colocar, en primer lugar, la justicia distributiva y opacar la justicia política. La justicia distributiva es la que se encarga de señalar de qué manera se deben distribuir los bienes en la sociedad, pero no se pregunta sobre quiénes son los que definen, ni de qué manera definen, el esquema de distribución. En cambio, la segunda figura de la justicia invierte la relación entre la justicia política y la justicia distributiva, colocando la primera delante de la segunda. Ahora, la pregunta pasa de ser ¿quién debe qué a quién? a la pregunta ¿cuáles son las razones que podemos compartir para organizar democráticamente el esquema de distribución? (Forst, 2014:1-5). 
Esta pregunta coloca en el centro el punto político de la justicia. Este punto consiste en que la determinación de la justicia se realiza por medio de un proceso democrático en el cual cada persona es considerada activa en la determinación del esquema de la justicia y no como pasivo receptor de reglas de justicia en cuya elaboración no ha participado. En este sentido, las personas son asumidas como autónomas, es decir, como capaces de participar en el debate sobre la justicia, debate basado en razones. La autonomía de las personas se expresa en lo que Forst denomina "derecho a la justificación". Cada persona cuenta con un derecho básico a exigir justificación respecto del esquema normativo en el que se encuentra inserto. Dichas justificaciones deben encontrarse basadas en razones mutuas y recíprocas. Si a alguien se le niega el derecho a la justificación, es claro que lo que está sucediendo es una injusticia.

El derecho a la justificación coloca a las personas en la situación de sujetos autónomos al momento de determinar las normas de la justicia. De esta manera, esta figura de la justicia coloca el punto político en la concepción de la justicia. Por ello, conectar el republicanismo con la concepción de la justicia que brota de esta figura libera la potencia emancipadora que se encuentra en las entrañas del proyecto republicano. La concepción del republicanismo desarrollada por Pettit, concepción en torno a la interpretación de la libertad como no dominación, permanece atrapada aún en la primera figura de la justicia. Es decir, tiene en mente la idea de que la justicia consiste en dar a cada cual lo que le corresponde de acuerdo con un esquema preestablecido.

\section{2.- La centralidad de la autonomía en el republicanismo positivo}

Una diferencia importante entre el liberalismo y el republicanismo es, de acuerdo con Pettit, la relación entre la libertad y la ley. Como vimos arriba, el liberalismo entiende que esa conexión es instrumental y externa mientras que el republicanismo entiende que es intrínseca y orgánica. De esta manera, para el republicanismo queda claro que la ley es una expresión de la libertad. Pero, si Pettit se mantiene en la primera figura de la justicia, sucede que no va a percibir la problematización democrática a la que debe ser sometida el conjunto de leyes. Dicho de otra manera, el problema del republicanismo de Pettit reside en que asume un conjunto de leyes como el entramado que vehicula la libertad. Las leyes no brotan de un procedimiento democrático basado en un intercambio de razones, sino que son asumidas como correctas por ser las leyes de un Estado republicano.

En cambio, la segunda imagen de la justicia permite concebir el republicanismo bajo la interpretación de la justicia como no dominación. Este giro termina por potenciar el punto político del republicanismo, al conectarlo con la justicia política. De esta manera, los términos de la justicia son puestos en el foco de la discusión democrática, cosa que no sucede con la propuesta de Pettit. Con este desplazamiento hacia la democratización del debate, Forst asume una posición kantiana respecto del republicanismo, que coloca a la autonomía y a la justicia política en el corazón del republicanismo.

La perspectiva de Kant -señala Forst- se encuentra ya en la segunda imagen de la justicia. Esto le permitiría al filósofo de Köninsberg tener una concepción positiva del republicanismo, mientras que Pettit se mantiene en una concepción negativa del mismo, pues se encontraría centrado en una versión social de la libertad negativa. La concepción kantiana del republicanismo sería positiva porque se encuentra centrado en la autonomía de la persona. De hecho, el paso de la primera a la segunda imagen de la justicia que Forst presenta implica el paso de considerar a las personas como pasivos a quienes se les asigna bienes de acuerdo con un esquema prestablecido de justicia a considerarlas como activos en el proceso de deliberación respecto del esquema de justicia, deliberación basada en el intercambio de razones.

En este sentido, Forst señala lo siguiente:

I call it "Kantian" republicanism because the autonomy of persons to be both authors and addressees 
of the law, which holds in the moral realm as well as in the legal and political spheres, with proper modification, is the basic idea. Public justification then is the medium of that kind of autonomy in the political realm (Forst, 2013:160).

Así, el proceso de deliberación basada en razones que conduce a la justificación pública colocaría a la autonomía de las personas en el centro del campo político. La concepción positiva del republicanismo de Kant y Forst se diferencia de la concepción negativa defendida por Pettit en un punto central: el lugar que tiene la autonomía. Mientras que en Pettit, la autonomía tiene un lugar secundario, en Kant y Forst tiene un lugar central. Esto es debido a que en la concepción de Pettit respecto de la justicia la autonomía se encuentra en una posición marginal, mientras que en concepción de justicia desarrolladas por Kant y Forst se encuentra en un lugar central. Y junto con la autonomía, el intercambio de razones mutuas y recíprocas se coloca en el centro de la concepción positiva del republicanismo. En este giro, el republicanismo entiende la misma autonomía en términos del intercambio de razones mutuas y recíprocas. 


\section{REFERENCIAS}

Alegría, C. (2017) La moral y la ambivalencia de los bienes. Un análisis básico de la teoría de la justicia social, en Ideas Valores, Volumen 66, Número 164, 293-316.

Alegría, C. (2015) La crisis como antinomia histórica: sobre la revelación de la verdad, en Giusti, Miguel, Raúl Gutiérrez y Elizabeth Salmón (eds.), La verdad nos hace libres. Sobre las relaciones entre filosofía, derechos humanos, religión y universalidad. Lima: PUCP.

Berlin, I. (2012) Dos conceptos de libertad en Berlin, Isaiah, Sobre la libertad. Madrid: Alianza Editorial.

Braithwaite, J. y P. Pettit (2015) No solo su merecido. Por una justicia penal que vaya más allá del castigo, México: Siglo XXI.

Forst, R. (2013) A Kantian Republican Conception of Justice as Nondomination, en Niederberger, Andreas y Philipp Schink, Republican Democracy. Liberty, Law and Politics. Edinburgh: Edinburgh University Pres.

Forst, R. (2014) The right to justification. New York: Columbia U. P.

Forst, R. (2014) Justificación y crítica. Perspectivas de una teoría crítica de la política. Madrid: Katz.

Kant, I. (2002) Fundamentación para una metafísica de las costumbres. Madrid: Alianza Editorial.

Kant, I. (2000) Crítica de la razón pura. México: FCE.

Korsgaard, C. (1993) The Reasons we can Share: An Attack on the Distinction between Agent-Relative and Agent-Neutral Values, en Social Philosophy and Policy, Volume 10, Issue 1 , Winter, 24-51.

Korsgaard, C. (2000) Las fuentes de la normatividad. México: UNAM.

Nagel, T. (1996) Igualdad y parcialidad. Bases éticas de la teoría política. Barcelona: Paidós.

Nagel, T. (1986) The View from Nowhere. Oxford: Oxford University Press.

Pettit, P. (1999) Republicanismo: una teoría sobre la libertad y el gobierno. Barcelona: Paidós.

Rawls, J. (1996) Liberalismo político. Barcelona: Grijalbo Mondadori.

Scanlon, T. (2003) Lo que nos debemos unos a otros ¿Qué significa ser moral?. Barcelona: Paidós.

Fecha de recepción: 06-04-18.

Fecha de aceptación: 09-05-18. 